\title{
Literatura entre terras desiludidas: as alteridades distorcidas de Brasil e Portugal
}

\section{Literature among disillusioned lands: distorted alterities of Brazil and Portugal}

Mestranda em Escrita Criativa no Programa de Pós-Graduação em Letras da Pontifícia Universi dade Catolica do Rio Grande do Sul (PUCRS). (17) https://orcid. org/0000-0002-9725-3519 E-mail: grichinitti@gmail.com
Gabriela Richinitti ${ }^{1}$ Programa de Pós-Graduação em Letras, Escola de Humanidades,

RESUM0: Brasileiros e portugueses têm em comum uma espécie de niilismo identitário: uma baixa autoestima que repercute em suas culturas e dificulta o posicionamento altivo no cenário global. A literatura, ao retratar os fluxos migratórios que ocorrem entre essas terras desiludidas, tem reforçado diversos estereótipos e percepções negativas acerca de ambos os países. Dessa forma, a efetivação de um intercâmbio cultural criativo entre os países se deixa abater pela infertilidade dos lugares-comuns. A breve análise de algumas obras exemplificativas ilustrará as constatações deste ensaio, reafirmando que a melhoria do diálogo intercultural depende da renovação das velhas narrativas.

Palavras-chave: Literatura lusófona; Migração; Estereótipo; Identidade.

ABSTRACT: Brazilian and Portuguese people have in common a kind of identity nihilism: a low self-esteem that reverberates in their cultures and hinders the haughty positioning in the global scenario. Literature, while portraying the migratory flows that occur between these disillusioned lands, has been consolidating lots of stereotypes and negative perceptions about both countries. Therefore, the achievement of a creative cultural exchange among both countries is frustrated by the infertility of the commonplaces. A brief review of some exemplary works will illustrate the conclusions of this essay, reaffirming that the improvement of intercultural dialogue depends on the renewal of the old narratives.

Keywords: Portuguese-language literature; Migration; Stereotype; Identity. 


\section{Niilismos identitários e alteridades distorcidas}

or niilismo identitário, entende-se a visão negativa de determinado povo sobre si: uma espécie de baixa autoestima coletiva que se funda na ideia de que outros países são, de alguma forma, superiores. Esse senso crônico de inferioridade, em vez de reverter em projetos e investimentos proativos nas potencialidades nacionais, culmina numa descrença paralisante quanto às perspectivas de futuro. 0 reforço de estigmas depreciativos, a rejeição de tradições, o desejo de evasão, o desprezo pela cultura local e as incessantes comparações com a realidade de outros lugares - geralmente percebidos de maneira idealizada - são sintomas da identidade niilista.

Portugal e Brasil manifestam negativismos dessa natureza. A forma como historicamente assumem a condição de territórios periféricos em relação às Nações consideradas hegemônicas reflete nas representações literárias exportadas pelas obras de alguns de seus autores mais conhecidos, como o português Eça de Queiroz (1845-1900) e o brasileiro Jorge Amado (1912-2001). No mesmo compasso, a literatura que retrata os fluxos migratórios entre os dois países - ambos desiludidos quanto às próprias qualidades - também contribuiu para replicar e reforçar diversos estigmas e desesperanças, alargando a zona de incompreensão que impossibilita qualquer projeto de efetivo diálogo transnacional.

Servindo à exportação de lugares-comuns e imagens estereotipadas, a língua portuguesa deixa de funcionar como fator de permeabilidade entre as fronteiras de Brasil e Portugal. Esforços integrativos - desde que empreendidos sem intuitos homogeneizantes, que serviriam apenas para neutralizar as riquezas identitárias de cada povo - poderiam se revelar vantajosos para os dois países, fortalecendo-os politicamente e abrindo espaços de partilha cultural. Inserida no projeto mais amplo da lusofonia - que abrange todos os Estados em que predomina a língua portu- guesa -, essa integração já não pode se sustentar em articulações de natureza colonialista, caracterizadas por vínculos de hierarquia e dominância. Para que se construa uma verdadeira alteridade - onde o encontro das diferenças promova intercâmbios criativos e diálogos de mútuo entendimento entre as regiões -, é necessário, antes, abrir novas percepções e possibilidades de vivência, rompendo os estereótipos e preconceitos que obstam a apreensão genuína do outro.

As alteridades distorcidas são, portanto, as leituras míopes e insuficientes que um povo faz sobre o outro, lastreadas por estereótipos e lugares-comuns. Este trabalho, ao investigar as relações literárias de Brasil e Portugal, propõe que a literatura lusófona não funcione apenas como solidificadora de narrativas herméticas e mantenedora de estigmas, mas sirva como espaço de intercâmbio criativo entre essas duas terras marcadas pela desilusão.

\section{Representações externas de Brasil e Portugal}

Antes de imergir no estudo de algumas obras literárias representativas, cabe examinar como os dois países percebem internamente suas identidades e as projetam no cenário internacional. Mapeando as origens, as similitudes e os desdobramentos dos niilismos identitários de Brasil e Portugal, será possível entender de que forma repercutem na literatura e, mais especificamente, nas narrativas que retratam os fluxos migratórios entre os dois países.

Em uma famosa crônica publicada no ano de 1958, Nelson Rodrigues detectou o senso de inferioridade do brasileiro - um certo niilismo identitário que o dramaturgo traduziu por "complexo de vira-lata” (RODRIGUES, 1993, p. 51 e 52). A consagração do diagnóstico parece ter corroborado seu próprio acerto, incorporando-se ao arsenal autodepreciativo do vocabulário 
popular. Não servindo propriamente a uma mudança de perspectiva, além de vira-latas, alçamo-nos de bom grado à condição de vira-latas complexados.

Ocorre que nascer vira-lata não é tão ruim quanto se resignar à condição de inferioridade, crendo-se predestinado às sobras e aos descartes, encolhendo-se diante das palavras de ordem daqueles que se entendem os donos legítimos do planeta. O Brasil é um vira-lata robusto, e seria ainda mais se conseguisse andar em uma matilha coesa e organizada. Dessa forma, a horizontalidade dos diálogos junto à comunidade internacional depende da postura das lideranças nacionais e à inteligência das estratégias de inserção diplomática, que se beneficiam de frentes de atuação coesas e articuladas.

Enxertado em meio às matrizes espanholas da América Latina, o país encontra dificuldades significativas para colocar-se num plano integrativo transnacional. Como a identidade das fronteiras não corresponde à identidade dos idiomas, surge um empecilho imediato à fluidez do diálogo intercultural e do intercâmbio com os territórios latino-americanos.

Mesmo o governo marcadamente neoliberal de Fernando Henrique Cardoso (1995-2003), alinhado ao programa ideológico norte-americana, percebeu a necessidade de políticas integrativas regionais para buscar a simetria das negociações exteriores. Como analisa José Guilhon Albuquerque, a aliança do Brasil com a América Latina durante o governo FHC fortaleceu sua representatividade no continente, rompendo a histórica relação de subordinação dos países do Sul às potências do Norte:

Em nenhum outro período, desde a Revolução de 30, o entorno regional do Brasil mereceu tanta prioridade. As vicissitudes internacionais, até o início da Guerra Fria, tornavam vitais as relações com a Europa e os Estados Unidos. A partir da década de 50 as necessidades do desenvolvimento levaram o Brasil a buscar fora da região os parceiros de que precisava para industrializar-se e modernizar-se. Foi apenas com a finalização do acordo da dívida externa, na década de 90, que o País teve condições de adotar políticas afirmativas no Continente, em contraposição às políticas defensivas que prevaleciam até então.
Com isso, a América do Sul - e particularmente o Cone Sul - ocupou o centro da política externa brasileira. Rubens Ricúpero chega a sugerir que, no permanente triângulo Brasil/EUA/América Latina, pela primeira vez a relação com o Norte do Continente ficou subordinada aos objetivos e prioridades das relações com o Sul (ALBUQUERQUE, 2006, p. 553).

A emergência do Brasil no cenário político internacional por meio de alianças com as Nações historicamente postas à margem dos debates globais demonstra a eficácia dessa estratégia para neutralizar o desequilíbrio de forças. Além disso, a postura assumida pelas autoridades diplomáticas também é fundamental ao prestígio do país. Nesse sentido, foi o governo de Luís Inácio Lula da Silva (2003-2011) que operou uma ruptura significativa da condição de subalternidade. O ativismo diplomático de Lula buscou consagrar a liderança do Brasil no cenário mundial, não permitindo que o poderio econômico e militar representasse óbice intransponível à implementação de uma postura altiva nos debates internacionais. Pela primeira vez, o complexo de vira-lata arrefecia consideravelmente no plano das relações exteriores, com o país assumindo um lugar proporcional à dimensão de sua cultura, de seu território, de suas riquezas naturais e de seu potencial econômico. Em uma manobra mais arrojada do que a de Fernando Henrique Cardoso, o ativismo diplomático de Lula não se deixou tolher por restrições estruturais, buscando ocupar espaços de poder em âmbito mundial:

A assunção de qualquer papel do Brasil como líder era visto, por FHC como o resultado da gradual preeminência econômica do País e deveria em princípio ser limitado à região, em vista da limitação dos recursos efetivamente disponíveis para a ação externa do Estado (em termos financeiros, obviamente, mas também militares e diplomáticos). Para o governo Lula, visivelmente, trata-se de um dos grandes objetivos políticos, e não necessariamente limitado apenas à região. Enquanto FHC modulava esse objetivo em função das percepções dos parceiros regionais (a começar pela Argentina), Lula parece acreditar que esse papel pode ser 
conquistado com o ativismo diplomático e as alianças estratégicas que estão sendo desenvolvidas com os parceiros já citados anteriormente. FHC tinha consciência dos limites estratégicos e da real capacidade econômica do Brasil, ao passo que para o governo Lula não parece existir limitações estruturais (orçamentárias e militares) a tal pretensão. Na prática, 0 exercício da liderança se revelou mais difícil do que antecipado idealmente nos discursos para consumo público (ALMEIDA, 2004).

A afirmação da identidade nacional nas instâncias políticas mundiais é importante para que se desfaçam as relações hierárquicas entre os Estados; o fortalecimento do Brasil no cenário internacional decorreu, em alguma medida, do abandono do complexo de vira-lata, e não o contrário. Isso porque, do outro lado da grade - fictícia, ao menos enquanto o sonho norte-americano de erguê-la na fronteira com o México não se consuma -, as grandes potências econômicas, políticas e militares não se constrangem do sentimento oposto: um certo complexo de pedigree, não raramente eivado de patriotismo agressivo, que age como mecanismo mantenedor das desigualdades diplomáticas.

Em meio aos demais países da América Latina, a gênese do Estado brasileiro tem a peculiaridade de estar atrelada a Portugal, que também experimenta sua espécie de niilismo identitário: dentro da União Europeia, sobrevive como país periférico, de segunda classe. Com todas as peculiaridades que os diferenciam, Brasil e Portugal interiorizaram em seus respectivos imaginários coletivos o senso de inferioridade.

As desconfianças dos portugueses quanto à dimensão de seus recursos produtivos, à importância político-econômica perante o continente europeu e às potencialidades de seu povo acentuaram-se no decorrer do século XIX. Já muito distante da ufania proporcionada pela Era dos Descobrimentos dos séculos XV e XVI, quando liderou as Grandes Navegações, Portugal participou timidamente da Revolução Industrial, assistindo ao enriquecimento da Inglaterra. Mesmo em comparação com as economias menos pujantes do norte da Europa, Portugal apresentava uma taxa de crescimento inferior, que o colocava entre os países mais pobres do continente:

Na primeira metade dos oitocentos, o país era dos mais pobres da Europa, com um rendimento per capita provavelmente $40 \%$ ou menos do inglês e entre $50 \%$ e $60 \%$ do nível atingido então por economias periféricas do Norte da Europa como a Dinamarca ou a Suécia (REIS, 2000, p. 244).

O descompasso de Portugal diante dos céleres avanços da civilização industrial contribuiu para reforçar a ideia de que o país passara a viver entre vizinhos maiores do que ele. É como se, imerso nos sonhos de um passado glorioso, houvesse adormecido por largos séculos, deixando-se ultrapassar e despertando em uma realidade onde nem mesmo aqueles que outrora subjugou reconheciam sua antiga grandeza. Não é difícil imaginar que essa mudança de posição - de pioneiro do expansionismo mundial à periferia do continente europeu - tenha atingido o espírito coletivo português, injetandolhe alguma dose de melancolia nostálgica e sentimento de inferioridade, quando não de ressentimento e mágoa diante do esquecimento a que foram relegados os grandiosos feitos do passado. Como preleciona Jaime Reis, a consciência quanto ao atraso do país tornou-se mais nítida no decorrer dos séculos XIX e XX:

Com os séculos XIX e XX, porém, tais dúvidas parecem ter-se tornado mais prementes e mais persistentes, ao mesmo tempo que formuladas com maior clareza analítica e cada vez mais focadas sobre o atraso industrial do país. A isto não terá sido alheia a percepção crescente e, como veremos, não infundada, de que Portugal estava efetivamente ficando mais e mais para trás à medida que na Europa, na América e mesmo no resto do mundo, a civilização industrial avançava a passos largos, gerando cada vez mais riqueza e meios de a reproduzir (REIS, 2000, 243).

A adesão da República Portuguesa à Comunidade Econômica Europeia (CEE), em 1977, representou uma tentativa integrar o país ao grupo dos 
Estados mais fortes. Afirmar que, à época, Portugal não passava de um pequeno território na periferia da Europa (com apenas 0,8\% do território, $1,3 \%$ da população e $1 \%$ da economia de todo o continente) não é nenhum exagero. Durante o século XX, seu PIB consistia em uma fração do padrão de vida europeu (oscilando entre $50 \%$ e $75 \%$ da média). Ademais, a língua portuguesa se encontra isolada dentro das fronteiras nacionais, dificultando a circulação da cultura e do povo para além dos limites territoriais (MONTEIRO; SOUSA; RAMOS, 2009, p. 817). Antes do processo de integração europeia, Bernardo de Vasconcelos e Sousa, Nuno Gonçalo Monteiro e Rui Ramos reconstroem a imagem de Portugal como um país obscuro e remoto, cuja personalidade mais conhecida era um jogador de futebol, e cujo objetivo com o projeto da CEE era se colocar entre os grandes:

Em termos europeus, fora durante muito tempo um país obscuro e remoto que só na década de 1960 começou a atrair turistas e a ter emigrantes nos outros Estados. O português mais conhecido na Europa, antes de 1974, era o jogador Eusébio. Neste contexto, a filiação europeia na década de 1970 pôde ser apresentada, pela elite política, como o império colonial na década de 30: uma maneira de não ser pequeno e marginal, para além da promessa de prosperidade, neste caso associado à pertença a um clube de países ricos (MONTEIRO; SOUSA; RAMOS, 2009, p. 817).

Assim como no Brasil vira-lata de Nelson Rodrigues, a melancolia e a fragilidade da autoestima portuguesa se deixaram apreender pela literatura de diversos períodos, substanciando crônicas, artigos e textos ficcionais. Entre 1880 e 1897, Eça de Queirós colaborou para a Gazeta de Notícias; no periódico carioca, o escritor português se encarregava dos assuntos europeus. Em dezembro de 1880, o também escritor Manuel Pinheiro Chagas acusou-o de ter chamado Portugal de um "país de bestas". A resposta de Eça de Queirós deixa transparecer o niilismo identitário de Portugal, um "povo de bem" visto pelo restante da Europa como uma "nação de medíocres", uma "nação de estúpidos":

O juízo que de Badajoz para cá se faz de Portugal não nos é favorável... Não falo aqui de Portugal, como estado político. Sob esse aspecto, gozamos uma razoável veneração. Com efeito nós não trazemos à Europa complicações importunas; mantemos dentro da fronteira uma ordem suficiente; a nossa administração é correctamente liberal; satisfazemos com honra os nossos compromissos financeiros. Somos o que se pode dizer um povo de bem... A Europa reconhece isto; e todavia olha para nós com um desdém manifesto. Porquê? Porque nos considera uma nação de medíocres digamos francamente a dura palavra, porque nos considera uma nação de estúpidos. Este mesmo Times...

Aqui eu citava o Times, o Daily Telegraph (poderia ter citado mil), que nos têm acusado de estúpidos, de mazorros e de intelectualmente fósseis. E depois acrescentava estas palavras minhas: - "Tais observações são decerto, além de descorteses, perversas! (QUEIRÓS, 1880, p. 27).

Ao acusar Pinheiro Chagas de haver descontextualizado suas palavras, Eça procurou afastar-se do estigma antipatriótico. Ainda assim, fica nítida a importância que o escritor português confere ao juízo de Estados europeus postos em condição de superioridade. Na crônica, Portugal aparece como um país alvejado pelos termos depreciativos de dois grandes periódicos britânicos.

Considerando que o negativismo identitário lusitano tem origem póscolonial, o sentimento de inferioridade brasileiro não pode ser imediatamente atribuído ao espírito de seus colonizadores, que, à época, ainda celebravam o arrojo e a coragem expansionista. Não é incomum, contudo, que se identifique no modelo de colonização implantado pela metrópole as raízes dos problemas socioeconômicos brasileiros. Em 2015, uma declaração do então presidente Luiz Inácio Lula da Silva - responsabilizando a colonização portuguesa pelos atrasos do Brasil contemporâneo - provocou forte reação na imprensa europeia. Sem adentrar no mérito da distribuição de culpas 
e responsabilidades, é possível perceber que as relações entre os dois maiores territórios de língua lusófona permanecem carregadas de tensões do passado. Além dessas zonas de atrito, o sentimento de inferioridade que perpassa o imaginário social de ambos os países dificulta a construção de uma alteridade qualificada.

Em continentes e contextos culturais distintos, Brasil e Portugal partilham da percepção negativa quanto à própria imagem: são povos com orgulho e esperança degradados, projetando suas insatisfações para além de suas fronteiras. $\mathrm{O}$ sentimento repercute em projetos individuais de migração e fuga, que não raramente culminam num intercâmbio populacional entre esses dois territórios desiludidos.

\section{Transitar entre terras desiludidas}

A verticalidade do olhar externo incide sobre o orgulho lusitano com força análoga à que comprime o Brasil a um espaço sempre desproporcional à sua verdadeira dimensão. A expressão artística de ambos se deixa atravessar por esse sentimento de desconfiança e descrença, ainda que com tonalidades diferentes, matizadas pelos períodos de crise ou prosperidade econômica. Nesse sentido, a literatura procura capturar os movimentos migratórios que sempre existiram, incentivados pela língua comum e por acordos que facilitam o trânsito entre os países.

De um e de outro lado, o perfil literário do migrante varia com o tempo; mais estáveis, contudo, são os cenários encontrados no avesso do sonho, imbuídos de lugares-comuns que provêm menos da realidade de cada espaço do que dos embates entre os registros culturais dissonantes. Em geral, as personagens se decompõem no ritmo em que se desintegram suas projeções; não raro, a esperança que animou a viagem encontra, em terras tropicais ou mediterrâneas, desfechos infelizes.
No imaginário europeu, repercute ainda a essência do mito formador da identidade brasileira, preconizado por Gilberto Freyre em Casa Grande \& Senzala, sua obra canônica. Lançadas ao fértil terreno do senso comum, as sementes floresceram tão proficuamente quanto os romances de Jorge Amado, um dos brasileiros mais lidos no exterior. Afinal, o autor de Gabriela, Cravo e Canela exporta um Brasil muito próximo ao de Freyre: miscigenado, lascivo, exótico, malandro, aromático, cordial, ardente, místico, pobre - um rol comprido de adjetivos que, de tão repisados, unem-se intuitivamente. Para Ilana Seltzer Goldstein, autora de $O$ Brasil best seller de Jorge Amado: literatura e identidade nacional, o autor constrói um Brasil cujas virtudes são a mestiçagem, a exaltação dos sentidos e prazeres sensuais, a festividade, a tolerância racial e a alegria de viver (GOLDSTEIN, 2002, p. 109-133).

Em suma, vende-se um país insculpido sobre a democracia racial utópica, que apenas pela ausência de um aprofundamento crítico consegue conviver com o outro Brasil best-seller: o da miséria e da violência. O romance Cidade de Deus, de Paulo Lins, exportou largamente esse lado avesso do país; o filme homônimo, roteirizado por Bráulio Mantovani, foi indicado ao Oscar no ano de 2004, nas categorias de melhor diretor, melhor roteiro adaptado, melhor edição e melhor fotografia.

Esses vetores qualitativos atuam sobre o imaginário do português que, por razões diversas, dirige-se ao Brasil. Na literatura contemporânea, a degeneração tropical ainda é bastante recorrente. Mais de um século depois, a maldição de Jerônimo - o imigrante lusitano que, na obra $O$ Cortiço, de Aluísio Azevedo, deixa-se seduzir e degenerar pela sensualidade de Rita Baiana - ainda parece assombrar a moral europeia.

Em Enquanto Lisboa Arde, o Rio de Janeiro Pega Fogo, de Hugo Tavares, o protagonista, fugindo da crise em Portugal, deixa-se enredar na atmosfera escaldante do Rio de Janeiro, onde as tentações fervem nas calçadas e avivam o sangue e os hormônios. As mulheres compõem a paisagem 
carioca, persuadindo o português como anúncios publicitários; a associação entre criminalidade, luxúria e calor também está presente no discurso do narrador:

No Posto 11, a minha visão, instigada pela lascívia da maconha, focou-se apenas nos detalhes: as pernas de uma skater, a escuridão que estranhamente reluzia na pele de uma preta cor de pantera, o osso de uma omoplata tatuada, a boca sem batom da hippie que vendia pulseiras, um caleidoscópio imparável de tentações, propaganda agindo sobre as minhas hormonas. Percebi que a minha determinação em ver, sem tocar ou provar, tinha as horas contadas. Dizem as estatísticas que o crime aumenta nas grandes cidades nos dias de calor. A sacanagem também.

(...)

No estúdio de tatuagens, os artistas conversavam sobre futebol e sobre uma gatinha surfista que "deu pró cara da sapataria". No Rio, as mulheres dão e os homens comem. É uma cómica ilusão de poder (GONÇALVES, 2013, n.p.).

Na literatura de Inês Pedrosa, a energia libidinosa penetra o corpo feminino numa ânsia a tal ponto primitiva que a protagonista julga-se capaz de farejar a carne, o sexo e até mesmo o movimento de enleio das raças:

Do cheiro a mar, bulício, perigo e ousadia que não encontro em Portugal. 0 cheiro a corpos que se mostram - o cheiro a carne e a sexo, à mistura de raças. 0 Brasil tem um odor a sobrevivência pura que me apaixona (...) (PEDROSA, 2008, p. 154).

No Brasil animalizado, desonesto, território de perdições - sem grandes compromissos além da festa e da concupiscência - ou na tonalidade opaca de Portugal - onde esmorecem as esperanças, as perspectivas são poucas e o enraizamento é impossível, como veremos na próxima obra estudada -, consolidam-se e se retroalimentam os mesmos estigmas ao longo do tempo. As experiências ficam reduzidas a estereótipos que, com ou sem lastro na realidade, não a abarcam com a amplitude que fazem crer, reproduzindo uma imagem cansada e pouco complexa dos dois países. Mesmo com a história partilhada e a língua comum, Brasil e Portugal não se entendem.

Inviabiliza-se, assim, qualquer projeto mais consistente daquilo que poderíamos chamar de cultura lusófona, uma zona de intercâmbio horizontal quase miticamente imaginada, onde os países integrantes abrem-se à experiência do outro e estabelecem entre si entendimentos capazes de reforçar mutuamente suas vozes e posições perante o mundo. Os discursos pós-coloniais têm utilizado o denominador comum da língua como substrato para a articulação com a literatura e cultura (FONSECA, 2013, p. 3).

O filósofo Eduardo Lourenço identifica, ainda, um orgulho nostálgico no povo português, condenado a rememorar as conquistas do passado e a nutrir uma vaidade ambígua em relação ao filho que, ao desenvolver sua independência, afastou-se para sempre da matriz colonial:

É mais do que claro que no imaginário brasileiro nem a palavra, nem a realidade da lusofonia, podem ter o mesmo sentido, quer dizer, a mesma função simbólica que no nosso, de antigos pais de filhos sempre maiores do que nós, condenados a viver, dentro da pequena casa lusitana, na pura nostalgia dos esplendores passados. Se esplendores foram, como os sonhámos ou, acaso, maiores ainda. Sempre fomos um povo de sonhos maiores do que nós. E só por tê-lo sido, mesmo na aberração ou na vertigem, nos consolamos e nos orgulhamos, até ao absurdo, de ser quem somos (LOURENÇO, 1999, p. 174-177).

São dois países que, perante o mundo, se veem em baixa autoestima - e que, entre si, tendem a reforçar mutuamente suas condições de lugares impossíveis e improfícuos, morredouro de todas as esperanças. Ao impelirem-se um em direção ao outro, perfazem voos tortos e rasos. Tangenciam o sonho e logo fracassam, numa desilusão próxima à dos versos que encerram o poema de Mário de Sá Carneiro: 
Assombro ou paz? Em vão... Tudo esvaído

Num baixo mar enganador d'espuma;

E o grande sonho despertado em bruma,

O grande sonho - ó dor! - quase vivido...

(...)

De tudo houve um começo... e tudo errou...

- Ai a dor de ser-quase, dor sem fim... -

Eu falhei-me entre os mais, falhei em mim,

Asa que se elançou mas não voou...

(SÁ-CARNEIRO, 2014, p. 39-40).

Embora os brasileiros formem a maior comunidade estrangeira em Portugal $^{1}$, a representação literária desse imigrante é mais escassa - contemporaneamente, poucas obras destacadas versaram sobre o tema dos brasileiros em Portugal. Por outro lado, a atenção que se continuam oferecendo à experiência do português no Brasil possivelmente representa um indício de que o sentimento lusitano continua impregnado da "nostalgia dos esplendores passados", conforme percebida por Eduardo Lourenço.

De parte do Brasil, o material comparativo rarefeito ${ }^{2}$ não serve para afirmações categóricas; mas, como a rigidez e a generalidade das categorias tem sido justamente o problema, o capítulo seguinte examinará um caso da literatura do século XXI. Em Estive em Lisboa e lembrei de você, de Luís Ruffato, o protagonista Sérgio busca as promessas de uma nova vida em terras lisboetas.

\footnotetext{
${ }^{1}$ Informação extraída do Relatório Estatístico Anual de 2016, promovido pelo Observatório das Migrações da República Portuguesa. REPÚBLICA PORTUGUESA. Indicadores de Integração de Imigrantes - Relatório Estatístico Anual (2016). Coord. Catarina Reis Oliveira; Natália Gomes. Disponível em: <https://www om acm govpt/documents/58428/383402/Relat\%C3\%B3rio+Estat\%C3\%ADstico +Anual+2016_pdf/f276bae0-d128-43b5-8558-cdb410249fd2>. Acesso em: 16 ago. 2018.

2 Este trabalho de pesquisa buscou reunir obras em língua portuguesa que captassem os fluxos migratórios entre Portugal e Brasil concentrando-se principalmente na literatura do final do século XX e início do século XXI As narrativas que retratam a experiência de brasileiros em terras portuguesas, contudo, mostraram-se bastante escassas, ao menos no que tange aos escritores de majuresas, no mercado editorial.
}

\section{A terra melancólica de Estive em Lisboa e lembrei de você}

No livro Estive em Lisboa e lembrei de você, lançado em 2009, o escritor Luiz Ruffato dá voz à história de Sérgio, brasileiro da cidade mineira de Cataguases. Após uma sequência de insucessos na vida, decide mudar-se para Portugal com o objetivo de enriquecer e retornar para o Brasil. À mesa do bar, amigos o convencem de que em Portugal sobram oportunidades "pros brasileiros e pros pretos", abundando dinheiro e faltando mão de obra em funções como pedreiro, manicure, garçom, pintor de parede e bombeiro. Impulsivamente, o rapaz assume a decisão, transformando-se de imediato em uma espécie de celebridade local - um projeto de novo rico que nunca se consuma.

A fixação da residência em Lisboa não chega a fazer parte dos planos - trata-se, desde o início, de uma relação utilitária. O brasileiro inverte o processo perpetrado pelos chamados "brasileiros de torna-viagem", portugueses que, a partir do século XVIII, viajavam ao Brasil com o intuito de enriquecer pelo ouro aluvial descoberto em Minas Gerais. Aliás, é em terras mineiras que começa a odisseia malsucedida de Sérgio.

Ocorre que o sonho se deteriora numa Lisboa já de início pintada como taciturna, velha, letárgica e infértil. O brasileiro mistura a impressão que faz da cidade à visão das pessoas, que também parecem infelizes e moribundas:

Passei dormindo meu primeiro dia em Portugal, debaixo da cobertas no Hotel do Vizeu, na Madragoa, um bairro antigo pra caramba, de ruinhas estreitas e casario maquiado, uma antiguidade tão grande que até as pessoas são passadas, velhas agasalhadas em xailes pretos, velhos de boinas de lã subindo-descendo devagar o ladeirame, sem ar, escorados nas paredes, gente extravagante que parece uma noite deitou jovem e acordou, dia seguinte, idosa, cheia de macacoa, vista fraca, junta dolorida, dente molengo, perna inchada, e, assustados, passaram a desconfiar de tudo, sempre enfezados, resmungando pra dentro, incompreensíveis, respondendo as perguntas com irritação, e, quando pus os pés em Lisboa, o rapaz olhou o retrato no passaporte, falei bom dia, nem respondeu (...) (RUFFATO, 2009, p. 39). 
Para a personagem de Inês Pedrosa, o Brasil cheira a sexo e à mistura de cores e corpos, remetendo à energia geradora e aos prazeres sensoriais. Já para o protagonista de Ruffato, Lisboa não passa de um lugar impotente e incompreensível, prenúncio da ruína absoluta, do mofo que aos poucos sufoca os sonhos de Sérgio. As imagens se contrapõem: entre a fertilidade imprudente e o definhamento melancólico, nenhum dos dois territórios parecem capazes de gerar bons frutos.

A dificuldade de adaptação do brasileiro encontra fundamento inclusive no discurso de um velho lusitano, seu Carrilho, que guarda do Brasil memórias prósperas, enquanto arrasta uma vida desgostosa em Lisboa:

Ia adoecendo com a friagem, comprei luva, meia, touca, blusa, camisa e calça, tudo de lã, e isso em plena primavera, como informou o seu Carrilho, "Prepare-se para o inverno, rapaz", de quem acabei chapa, um tipo que gosta dos brasileiros e detesta os conterrâneos, sempre que pode fala mal, por tudo e por nada, traumatizado com os patrícios, "Cheguei a estar rico na tua terra", onde desembarcou sozinho, de navio, om doze, treze anos (...) (RUFFATO, 2009, p. 47).

Transitando entre os extremos do país do futuro que nunca chega (Brasil) e do passado estéril (Portugal), Sérgio percebe que, para um sujeito pobre e de pouca instrução, pouco importa o lugar. Os países repetem a desigualdade interna, as relações opressivas, os preconceitos, a concentração de poder. No discurso de Rodolfo, outro imigrante brasileiro em terras portuguesas, aparece a indignação com a injustiça incontornável que recai sobre aqueles que, sem posses, buscam com honestidade um destino melhor:

"Nós estamos lascados, Serginho", aqui em Portugal não somos nada, "Nem nome temos", somos os brasileiros, "E o que a gente é no Brasil?", nada também, somos os outros, "Eta paisinho de merda", terra de ladroagem e safadeza!", ele, meio alto, quase-discursava, "Pra se dar bem, o cabra tem que ser político ou bandido, que é quase a mesma coisa, aliás", porque o trabalhador, aquele que bate-cartão ou que capina sol a sol, este morre à-míngua (...) só quem tem berço, as famílias que exploram o Brasil desde sempre, e que pra isso fazem política (...) (RUFFATO 2009, p. 78).

Os males e prazeres atribuídos ao brasileiro derivam de sua flexibilidade moral; já as mazelas do espírito português se encarnam na personagem do Poeta. Ao meio-dia em ponto, rigorosamente, ele almoça no restaurante onde Sérgio começa a trabalhar. Causa forte impressão no brasileiro por ser "encovado de pesadelo, vestimenta preta, calça, meia, sapato, casaco, só a camisa alvejada, amassada" (RUFFATO, 2009, p. 50-52). Ao final, o sujeito tétrico e vetusto se revela um tremendo embuste, falseando autógrafos de escritores em livros velhos para revendê-los a um preço maior. A imoralidade portuguesa reveste-se de uma aparência intelectual; o respeito que impõe é vazio de qualidades.

No somatório das dores de Serginho, resulta que o Brasil - ao qual ele já não pode retornar, por ocasião do extravio do passaporte - se sai melhor pela riqueza afetiva, que, em Portugal, só se encontra em outros brasileiros ou nos cidadãos que recusam abertamente o mau-humor do povo lusitano. A potência narrativa da obra de Luiz Ruffato acaba por corresponder à previsibilidade dos estereótipos. A preocupação em romper os lugarescomuns se concentra no protagonista; ingênuo, bondoso e sensível, Sérgio não condiz com a malandragem atribuída ao brasileiro.

\section{Literatura para romper os estigmas}

No livro de Luiz Ruffato, a representação da realidade portuguesa reafirma a noção de que Portugal é uma terra velha e cinzenta, sepultada no passado. $\mathrm{O}$ brasileiro honesto que aposta sua felicidade em Lisboa encontra apenas uma série de ludíbrios e hostilidades. 
Do outro lado, a raiz dos problemas de representação do Brasil em grande parte da literatura escrita por portugueses parece estar na crença de que se pode interpretar a fundo um povo através das imagens que pululam na mídia de massas. Ou ainda: na ideia de que visitar um pedaço de terra de um país com dimensões continentais é suficiente para abarcá-lo por inteiro.

As representações que circulam na cultura atuam sobre o imaginário coletivo de modo a criar nele expectativas. Impossível medir em que grau o estigma que marca o imigrante brasileiro o entrega já em descrédito ao mundo, fadado a trabalhos secundários e a funções de subserviência. Para as mulheres, o problema adquire outra tonalidade: a sexualização que recai sobre seus corpos repercute como uma ameaça ao núcleo familiar europeu.

Em 2003, um movimento conhecido como "Mães de Bragança” protestou contra a chegada das brasileiras à pacata cidade portuguesa de Bragança, sob o argumento de que vinham prostituir-se, seduzir maridos e destruir lares. ${ }^{3}$ A ideia de que a sensualidade tropical possui um feitiço irresistível sobre os homens despeja toda a responsabilidade sobre o gênero feminino - não há muito espaço para que as mulheres estigmatizadas busquem outra espécie de destino.

Desonestidade, ânimo para festas sem fim, descompromisso e desinteresse pelo trabalho: o certo é que essas qualidades - propagadas pelas telenovelas, de grande penetração em Portugal, e pela literatura de ambos os países - não depõem a favor do imigrante brasileiro. De outro lado, frequentemente as experiências que o estrangeiro espera viver no Brasil aparecem com feições de utopia selvagem: sexo, liberdade, misticismo.

A matéria cultural que o Brasil exporta com as telenovelas - inaugurada por Gabriela, Cravo e Canela, exibida nos televisores portugueses em

3 Merece leitura a notícia intitulada Mães de Bragança passaram a ir aos salões de beleza, que se encontra
disponível em: <https://www.dn.pt/sociedade/interior/maes-de-braganca-passaram-a-ir-aos-saloesde-beleza-e-pensam-no-divorcio-5227975.html>. Acesso em: 13 set. 2017.
1975 - solidifica a imagem monocromática da realidade do país. Essas narrativas não têm grandes ambições de desapontar os lugares-comuns e os estereótipos, pois fundam sua larga aceitação no fato de serem extremamente palatáveis. Basta perceber que, na tradição da telenovela, é praxe que o bem triunfe e o mal fracasse ou sofra transformações morais. Os mesmos enredos esquemáticos se repetem entre as exaustivas sequências de praias, mulheres e montanhas cobertas de sol. A alegria atávica e incansável do povo imprime-se aos núcleos pobres, que, entre desventuras e dificuldades, convivem numa vida boêmia pulsante.

Por outro lado, dentro do Brasil, ainda não se desintegrou a dicotomia colonial entre Novo e Velho Mundo. Ao menos é esse o sentimento que transparece no texto de Ruffato, onde Lisboa aparece como território lúgubre. Em Portugal, a felicidade inata ao brasileiro esmorece até chegar ao tom grisalho de construções vetustas e de um céu pintado cinzento.

Entre Brasil e Portugal, é como se projetassem um no outro as qualidades de que se ressentem - sempre imbuídos daquela baixa autoestima com que historicamente convivem. O sentimento de inferioridade e desilusão se acentua durante as crises econômicas e políticas, quando a desesperança estimula a busca de novos caminhos. Na literatura, a alteridade conspurcada por séculos de retratos grotescos, imagens distorcidas e interpretações superficiais leva ao desterro, à deformação identitária e à incompreensão mútua. Eternamente imbricados pela língua, Brasil e Portugal ainda não estabeleceram uma zona de permuta que poderíamos chamar de criativa voltada à renovação das possibilidades narrativas, à empatia intercultural e à revisão dos preconceitos e estereótipos.

A literatura, contudo, tem o potencial de transgredir essas representações, construídas a partir de ideias que se enraizaram no imaginário coletivo. A potência inventiva do escritor exacerba-se quando ele é capaz de mostrar o que escapa à vista cansada, de contar as histórias marginais, de subverter o 
clichê sem provocar a descrença de seus leitores; pode estabelecer vínculos alternativos, propor outras investidas e expandir - ainda que ficcionalmente - o registro de nossas vivências. Se Brasil e Portugal guardam, por razões da história e da língua, um interesse mútuo, é fundamental que se qualifiquem as leituras de um sobre o outro. 0 arrefecimento da histórica sina de transitar entre duas terras profundamente desiludidas depende da abertura de novos caminhos. Na medida em que possa reinventar as velhas narrativas e repensar os estigmas, a língua portuguesa parece ser a ferramenta ideal para a construção de um espaço de fortalecimento e enriquecimento cultural mútuo.

\section{Referências}

ALBUQUERQUE, José Augusto. Sessenta anos de política externa brasileira (1930-1990): crescimento, modernização e política externa. Rio de Janeiro: Lúmen Júris, 2006.

ALMEIDA, Paulo Roberto de. Uma política externa engajada: a diplomacia do governo Lula. Revista Brasileira de Política Internacional, Brasília, v. 47, n. 1, 2004. Disponível em: <http://www.scielo.br/scielo.php?script=sci_arttext\&pid=S0034-73292004 000100008>. Acesso em: 24 jun. 2018. DOI: http://dx.doi.org/10.1590/S0034-7329 2004000100008

FREYRE, Gilberto. Casa-Grande \& Senzala: formação da família brasileira sob o regime da economia patriarcal. 52. ed. São Paulo: Global, 2013.

FONSECA, Ana Margarida. Em português nos entendemos? Lusofonia, literatura-mundo e as derivas da escrita. Configurações [online] n. 12, 2013, 27 out. 2014. Disponível em: <http://configuracoes.revues.org/2041>. Acesso em: 16 ago. 2018. DOI: http://dx.doi. org/10.4000/configuracoes.2041

GOLDSTEIN Seltzer, Ilana. O Brasil best seller de Jorge Amado: literatura e identidade nacional. Rio de Janeiro: SENAC, 2000.

GONÇALVES, Hugo. Enquanto Lisboa arde, o Rio de Janeiro pega fogo. Lisboa: Casa das letras, 2013.

LINS, Paulo. Cidade de Deus. São Paulo: Companhia das Letras, 2002.
LOURENÇO, Eduardo. A Nau de Ícaro seguido de Imagem e Miragem de Lusofonia. Lisboa: Gradiva, 1999

MATOZZI, Martina. Portugueses de torna-viagem: a representação da emigração na literatura portuguesa. 2016. Tese de doutoramento - Universidade de Coimbra. Disponível em: <http://hdl.handle.net/10316/29114>. Acesso em: 01 nov. 2017.

MONTEIRO, Nuno Gonçalo; RAMOS, Rui; SOUSA, Bernardo Vasconcelos e. História de Portugal. Lisboa: A Esfera dos Livros, 2009.

PEDROSA, Inês. A eternidade e o desejo. Rio de Janeiro: Objetiva, 2008.

QUEIRÓS. Eça de. Notas contemporâneas. Disponível em: <http://docs11.minhateca. com.br/928350692,BR,0,0,E\%C3\%A7a-de-Queir\%C3\%B3s---Notas-Contempor\% C3\%A2neas.pdf>. Acesso em: 11 nov. 2017.

REIS, Jaime. Causas históricas do atraso econômico português. In: TENGARRINHA, José (Org.). História de Portugal. Bauru: EDUSC; São Paulo: UNESP; Lisboa: Instituto Camões, 2000

RODRIGUES, Nelson. À sombra das chuteiras imortais: crônicas de futebol. São Paulo: Cia. das Letras, 1993.

RUFFATO, Luiz. Estive em Lisboa e lembrei de você. São Paulo: Cia. das Letras, 2009. SÁ-CARNEIRO, Mário de. Poesia reunida. Rio de Janeiro: Nova Fronteira, 2014.

SILVA, André Luiz Reis da. O Brasil diante da globalização: a política externa do governo Fernando Henrique Cardoso (1995-2002). Revista Carta Internacional, Associação Brasileira de Relações Internacionais (ABRI). v. 7, n. 1, p. 20-34, jan.-jun. 2012.

Recebido em 26/06/2018

Aceito em 07/09/2018. 